\title{
Short Communication \\ Hypermethylation of multiple genes as clonal markers in multicentric hepatocellular carcinoma
}

\author{
S Nomoto*,', T Kinoshita', K Kato', S Otani', H Kasuya', S Takeda', N Kanazumi', H Sugimoto' and A Nakao' \\ 'Department of Surgery II, Nagoya University School of Medicine, 65 Tsurumai-cho, Showa-ku, Nagoya 466-8550, Japan
}

\begin{abstract}
Hepatocellular carcinoma (HCC) is highly malignant and prone to multicentric occurrence. Differentiation between a true relapse of $\mathrm{HCC}$ and a second primary tumour appearing is of clinical importance. At this point, no convenient method is available to determine the origin of these HCCs. Tissue samples were obtained from 19 patients and analysed for the promoter hypermethylation status of multiple tumour suppressor genes ( $p$ /6, DAP-Kinase, MGMT, GSTPI, APC, RIZI, SFRPI, SFRP2, SFRP5, RUNX3, and SOCSI) using methylation-specific PCR (MSP). Methylation status was used to determine tumour clonality. In each of the 19 cases, at least one tumour was recognised as having an aberrantly methylated gene. The frequency of the methylation in tumour tissue was $57.1 \%$ in p 16, 2.4\% in DAP-kinase, 23.8\% in GSTPI, 90.5\% in APC, 45.2\% in RIZI, 64.3\% in SFRPI, 59.5\% in SFRP2, 28.6\% in SFRP5, 47.6\% in RUNX3, and $54.8 \%$ in SOCSI, while in MGMT, no aberrant methylation was detected. The methylation status of these genes was assessed using MSP as being either positive or negative, and was used to determine the tumour clonality. The clonality of every tumour could be decided even with lesions that could not be judged by clinical diagnosis or by another molecular method (mt DNA mutation). Determining the methylation status of multiple genes in multicentric HCC was useful as a clonal marker and provided useful information for characterising the tumour. From our findings, multicentric HCCs tend to occur more independently than metastatically from the original tumour. Expanded study should be pursued further for a better understanding of the molecular mechanism of hepatocarcinogenesis.
\end{abstract}

British Journal of Cancer (2007) 97, 1260-1265. doi:I0.1038/sj.bjc.66040 I6 www.bjcancer.com

Published online 30 October 2007

(c) 2007 Cancer Research UK

Keywords: hepatocellular carcinoma; multicentric occurrence; promoter hypermethylation; clonality; real-time methylation specific PCR

One of the most frequent tumour types worldwide is hepatocellular carcinoma (HCC). It is most commonly associated with chronic hepatitis $\mathrm{B}$ and $\mathrm{C}$ virus infections, with chronic exposure to the mycotoxin, aflatoxin B1 (AFB1), and is a complication of alcoholic cirrhosis. Death is often due to liver failure associated with cirrhosis and/or rapid outgrowth of multilobular HCC (Feitelson et al, 2002). Although early HCC may be cured by surgical resection, the central issue of this fatal disease is that it is prone to multicentric occurrence. The progression and outcome of truly relapsed HCC are distinct compared to a second primary tumour, and thus clonal analysis of initial and recurrent HCC is of clinical significance. Although several studies have addressed HCC clonal determination (Yamamoto et al, 1999; Chen et al, 2000; Ochiai et al, 2000; Nomoto et al, 2002), the reported molecular methods are still of limited clinical use or are technically quite challenging.

The development of HCC is a multistep process associated with changes in host gene expression, some of which correlate with the appearance and progression of tumour. Loss of heterozygosity and several types of mutations in tumour suppressor genes are reported to be involved in cancer development (Feitelson et al, 2002).

*Correspondence: Assistant professor S Nomoto;

E-mail: snomoto@med.nagoya-u.ac.jp

Received 8 June 2007; revised 24 August 2007; accepted 5 September 2007; published online 30 October 2007
Recently, epigenetic silencing is also considered to be a significant contributor to human carcinogenesis. Silencing of tumour suppressor genes by methylation of the CpG-rich promoter region has been reported in many kinds of human cancers. Some tumour suppressor genes such as p16, VHL, and MLH1 have been found to harbour promoter hypermethylation associated with loss of protein expression in cancer cells (Herman et al, 1994, 1998; Merlo et al, 1995). Several tumour types have also shown aberrant methylation at the CpG island in other genes, including the FAP-associated gene APC (Esteller et al, 2000), detoxifying gene GSTP1 (Lee et al, 1994), DNA repair gene MGMT (Esteller et al, 1999a), the potential metastasis inhibitor gene DAPkinase (Esteller et al, 1999b), and Rb interact gene RIZ1 (Du et al, 2001). Members of the frizzled-related protein family (SFRP-1, -2 , and -5 ), receptors for Wnt family members, were also reported to show promoter hypermethylation in colorectal cancers (Suzuki et $a l, 2002)$. We have reported previously hypermethylation of RUNX3 gene, locus at 1p36, where chromosomal deletion has frequently been found in various types of cancers, including HCC (Mori et al, 2005). Aberrant methylation was found in $65 \%$ of primary HCC tumour samples in SOCS1 gene (Yoshikawa et al, 2001).

In the present study, we analysed the promoter hypermethylation status of the human p16, MGMT, GSTP1, DAP-kinase, APC, RIZ1, SFRP1, SFRP2, SFRP5, RUNX3, and SOCS1 genes in the multiple tumour DNA and the corresponding normal DNA of 
HCC, and tried to apply it to determine their clonality. The clonality of all of the multiple lesions could be identified by this combined analysis to determine the promoter hypermethylation status of multiple tumour suppressor genes.

\section{MATERIALS AND METHODS}

\section{Clinical HCC samples}

Simple nodular HCC and adjacent nontumourous liver tissues from 19 patients, which were used in this study, were surgically resected in Nagoya University Hospital between 1989 and 2000. Thirteen of the 19 patients had synchronous multiple HCC, which were resected during their first operation. In the other six patients, hepatic tumours reappeared between 10 months and 5 years after the first curative operation, and they were resected by a surgical approach. Serologic markers for hepatitis B and $C$ virus infections and $\alpha$-fetoprotein levels were recorded.

\section{DNA extraction}

All specimens were immediately fresh-frozen after the resection and stored at $-80^{\circ} \mathrm{C}$. Serial $10 \mu \mathrm{m}$ sections were cut with a microtome. After staining with haematoxylin and eosin for the histologic examination, the other sections were used for DNA extraction. With the exception of a small part comprised of fatty and necrotic cells, nearly all $(>80 \%)$ of our sections were cancerous in nature. Normal and tumour DNA were prepared as described previously (Goelz et al, 1985).

\section{Methylation-specific PCR}

Sodium bisulphite treatment converts nonmethylated cytosine residues to uracil, while methylated cytosine within CpG islands remains unaffected. Briefly, $2 \mu \mathrm{g}$ of DNA was denatured by $\mathrm{NaOH}$ and modified by sodium bisulphate. DNA samples were then purified using the Wizard purification resin (Promega Corp., Madison, WI, USA), treated again with $\mathrm{NaOH}$, precipitated with ethanol, and resuspended in water. The primers and PCR conditions used in this study are summarised in Table 1. Nonmethylated promoter-specific PCR was always performed as well for each gene.

Amplifications were carried out in 96-well plates. All samples were run in triplicate and repeated in quadruple if any difference was noted. Each plate included multiple water blanks for a negative control. Lymphocyte DNA from a healthy individual was used as the negative control for 11 of the genes. The same lymphocyte DNA was methylated in vitro with excess Sss I Methyltransferase (New England Biolabs Inc., Beverly, MA, USA) to generate completely methylated DNA at all $\mathrm{CpG}$ and used as the positive control. Each PCR product was loaded directly onto $2.5 \%$ agarose gels, stained with ethidium bromide, and visualised under ultraviolet illumination.

\section{Determining tumour clonalities}

Tumour clonality was determined by the methylation status of multiple tumour suppressor genes. Basically, when the methylation status of the genes was the same as the original tumour, we assumed that the tumour was a metastatic lesion. Because of the loss of progression advantage of tumorigenesis, and if there were a loss of promoter methylation at least in the second or third lesion in a gene, those tumours were determined as independent. Thus, we supposed that a metastatic tumour could gain promoter hypermethylation in a gene that was not methylated in the first tumour. The clonality determined by the methylation status of the genes was compared with clinical diagnosis or the decision according to the mutation status in the mitochondrial genome (Nomoto et al, 2002).

Table I Summary of primer sequences and PCR product size

\begin{tabular}{|c|c|c|c|}
\hline Gene & Forward $5^{\prime}-3^{\prime}$ & Reverse $5^{\prime}-3^{\prime}$ & Size \\
\hline MGMT & CGAATATACTAAAACAACCCGCG & GTATTIITTCGGGAGCGAGGC & 122 \\
\hline DAPKI & GGATAGTCGGATCGAGTTAACGTC & CCСTCCCAAACGCCGA & 101 \\
\hline RIZI & GGATTCGCGGTGATTACGA & CTACGAAACTAAAAAACTCCGAAAC C & 121 \\
\hline SFRPI & CGTTCGCGAGGGAGGCGATT & AACCGCCCCGCGCAACCAAT & 97 \\
\hline$R \cup N \times 3$ & CGTCGGGTTAGCGAGGTTTC & GCCGCTACCGCGAAAAACGA & 120 \\
\hline sOCSI & CGCGCGGGGTTITCGTAGTA & CTAACTCCAACCGTCCGACC & 130 \\
\hline
\end{tabular}

Table 2 Summary of results of aberrant methylation

\begin{tabular}{|c|c|c|c|c|c|}
\hline Gene & $\begin{array}{c}\text { Tumours in multiple HCC } \\
\text { case }(n=42)\end{array}$ & $\begin{array}{c}\text { Normals in multiple HCC } \\
\text { case }(n=19)\end{array}$ & $\begin{array}{l}\text { Tumours in single } \\
\text { HCC case }(n=32)\end{array}$ & $\begin{array}{l}\text { Normals in single } \\
\text { HCC case }(n=32)\end{array}$ & $\begin{array}{c}\text { Normal liver } \\
\quad(n=17)\end{array}$ \\
\hline$p / 6$ & $24(57.1 \%)$ & $0(0 \%)$ & $21(65.5 \%)$ & $0(0 \%)$ & $0(0 \%)$ \\
\hline MGMT & $0(0 \%)$ & $0(0 \%)$ & I (3.1\%) & $0(0 \%)$ & $0(0 \%)$ \\
\hline GSTPI & $12(28.6 \%)$ & | (5.2\%) & $10(31.3 \%)$ & I (3.2\%) & $0(0 \%)$ \\
\hline APC & 33 (78.6\%) & $13(68.4 \%)$ & $28(87.5 \%)$ & 22 (68.8\%) & $15(88.2 \%)$ \\
\hline DAPKI & I (2.4\%) & $2(10.5 \%)$ & $0(0 \%)$ & $0(0 \%)$ & $0(0 \%)$ \\
\hline$R|Z|$ & $20(45.2 \%)$ & | (5.2\%) & $18(56.3 \%)$ & $0(0 \%)$ & | (5.9\%) \\
\hline SFRPI & $27(64.3 \%)$ & $9(47.4 \%)$ & $18(56.3 \%)$ & $14(43.8 \%)$ & | (5.9\%) \\
\hline SFRP2 & $25(59.5 \%)$ & $10(52.6 \%)$ & $17(53.1 \%)$ & $17(53.1 \%)$ & $2(11.8 \%)$ \\
\hline SFRP5 & $12(28.6 \%)$ & $2(10.5 \%)$ & $9(28.1 \%)$ & $3(9.4 \%)$ & I (5.9\%) \\
\hline RUNX3 & $20(47.6 \%)$ & $2(10.5 \%)$ & $15(46.9 \%)$ & $2(6.3 \%)$ & | (5.9\%) \\
\hline SOCSI & $23(54.8 \%)$ & I (5.2\%) & $15(46.9 \%)$ & I (3.2\%) & $0(0 \%)$ \\
\hline
\end{tabular}

Abbreviation: $\mathrm{HCC}=$ hepatocellular carcinoma. 
Table 3 Information of the patients and tumours

\begin{tabular}{|c|c|c|c|c|c|c|c|}
\hline Case & Sex & $\begin{array}{l}\text { Age } \\
\text { (year) }\end{array}$ & $\begin{array}{l}\text { Lag } \\
(\mathrm{mo})\end{array}$ & $\begin{array}{l}\text { HBs-Agl } \\
\text { HCV-Ab }\end{array}$ & Cirrhosis & Size $(\mathrm{cm})$ & Diff \\
\hline I & $M$ & 63 & 38 & $-1+$ & + & $\begin{array}{c}0.8 \times 0.8 \times 0.6 \\
0.6 \times 0.6 \times 0.5 \\
2 \times 1.7 \times 1.3\end{array}$ & $\begin{array}{l}\text { Mod } \\
\text { Mod } \\
\text { Mod }\end{array}$ \\
\hline 2 & $M$ & 71 & 10 & $-1-$ & + & $\begin{array}{c}11 \times 9 \times 8 \\
2 \times 1.8 \times 1.6 \\
2.9 \times 2.2 \times 1.8\end{array}$ & $\begin{array}{l}\text { Mod } \\
\text { Mod } \\
\text { Mod }\end{array}$ \\
\hline 3 & $M$ & 59 & $\begin{array}{l}15 \\
15\end{array}$ & $-1+$ & + & $\begin{array}{c}3 \times 3 \times 3 \\
2.1 \times 2 \times 1.8 \\
0.9 \times 0.9 \times 0.9\end{array}$ & $\begin{array}{l}\text { Mod } \\
\text { Mod } \\
\text { Mod }\end{array}$ \\
\hline 4 & $\mathrm{~F}$ & 57 & 116 & $+1-$ & + & $\begin{array}{c}4 \times 3.5 \times 3.5 \\
1 \times 1 \times 0.8\end{array}$ & $\begin{array}{l}\text { Mod } \\
\text { Mod }\end{array}$ \\
\hline 5 & $M$ & 61 & 47 & $-1+$ & + & $\begin{array}{c}2.5 \times 2.3 \times 2.1 \\
3 \times 2.6 \times 2.3\end{array}$ & $\begin{array}{l}\text { Mod } \\
\text { Mod }\end{array}$ \\
\hline 6 & $M$ & 36 & 65 & $+1-$ & + & $\begin{array}{l}3 \times 3 \times 2 \\
3 \times 3 \times 1\end{array}$ & $\begin{array}{l}\text { Mod } \\
\text { Mod }\end{array}$ \\
\hline 7 & $M$ & 68 & & $-/+$ & + & $\begin{array}{c}3 \times 3 \times 3 \\
2.7 \times 2.7 \times 2.5\end{array}$ & $\begin{array}{l}\text { Mod } \\
\text { Mod }\end{array}$ \\
\hline 8 & $M$ & 54 & & $-1-$ & - & $\begin{array}{c}10 \times 9.5 \times 8.5 \\
3 \times 3 \times 2\end{array}$ & $\begin{array}{l}\text { Mod } \\
\text { Mod }\end{array}$ \\
\hline 9 & $M$ & 69 & & $-1+$ & + & $\begin{array}{c}4 \times 4 \times 4 \\
1.5 \times 1.5 \times 1.5\end{array}$ & $\begin{array}{l}\text { Mod } \\
\text { Mod }\end{array}$ \\
\hline 10 & $M$ & 47 & & $+1-$ & + & $\begin{array}{c}8.8 \times 8 \times 7.5 \\
2 \times 2 \times 1.5\end{array}$ & $\begin{array}{l}\text { Mod } \\
\text { Mod }\end{array}$ \\
\hline | | & $M$ & 49 & & $-1+$ & + & $\begin{array}{c}3 \times 2.4 \times 2.4 \\
3 \times 2.2 \times 2\end{array}$ & $\begin{array}{l}\text { Mod } \\
\text { Mod }\end{array}$ \\
\hline 12 & $M$ & 56 & & $-1-$ & - & $\begin{array}{c}5 \times 5 \times 4.7 \\
2.2 \times 2 \times 1.8\end{array}$ & $\begin{array}{l}\text { Mod } \\
\text { Mod }\end{array}$ \\
\hline 13 & $M$ & 72 & & $-1+$ & + & $\begin{array}{c}2.5 \times 1.8 \times 1.5 \\
2 \times 1.6 \times 1.2\end{array}$ & $\begin{array}{l}\text { Mod } \\
\text { Well }\end{array}$ \\
\hline 14 & $M$ & 54 & & $-1+$ & + & $\begin{array}{c}2 \times 2 \times 2 \\
0.7 \times 0.6 \times 0.6\end{array}$ & $\begin{array}{l}\text { Mod } \\
\text { Well }\end{array}$ \\
\hline 15 & $M$ & 65 & & $-1+$ & + & $\begin{array}{c}4.5 \times 4 \times 4 \\
4.5 \times 3.5 \times 3\end{array}$ & $\begin{array}{l}\text { Mod } \\
\text { Mod }\end{array}$ \\
\hline 16 & $\mathrm{~F}$ & 63 & & $-1+$ & + & $\begin{array}{c}3 \times 2.4 \times 2 \\
2 \times 1.7 \times 1.5\end{array}$ & $\begin{array}{l}\text { Mod } \\
\text { Mod }\end{array}$ \\
\hline 17 & $M$ & 56 & & $-/+$ & + & $\begin{array}{l}1.9 \times 1.2 \times 1.2 \\
1.4 \times 1.2 \times 1.2 \\
1.3 \times 1.2 \times 1.1\end{array}$ & $\begin{array}{l}\text { Mod } \\
\text { Mod } \\
\text { Mod }\end{array}$ \\
\hline 18 & $\mathrm{~F}$ & 66 & & $-1+$ & + & $\begin{array}{l}2.2 \times 1.9 \times 1.8 \\
1.6 \times 1.4 \times 1.4\end{array}$ & $\begin{array}{l}\text { Mod } \\
\text { Mod }\end{array}$ \\
\hline 19 & $M$ & 60 & & $-/+$ & + & $\begin{array}{l}3.6 \times 3.4 \times 3 \\
2.4 \times 2.2 \times 2\end{array}$ & $\begin{array}{l}\text { Poor } \\
\text { Mod }\end{array}$ \\
\hline
\end{tabular}

Lag means the time between the first and second operation (mo = month).

\section{RESULTS}

Promoter hypermethylation of tumour suppressor genes in HCC tissue

We checked the status of promoter hypermethylation for 11 genes that were reported to show frequent promoter hypermethylation in

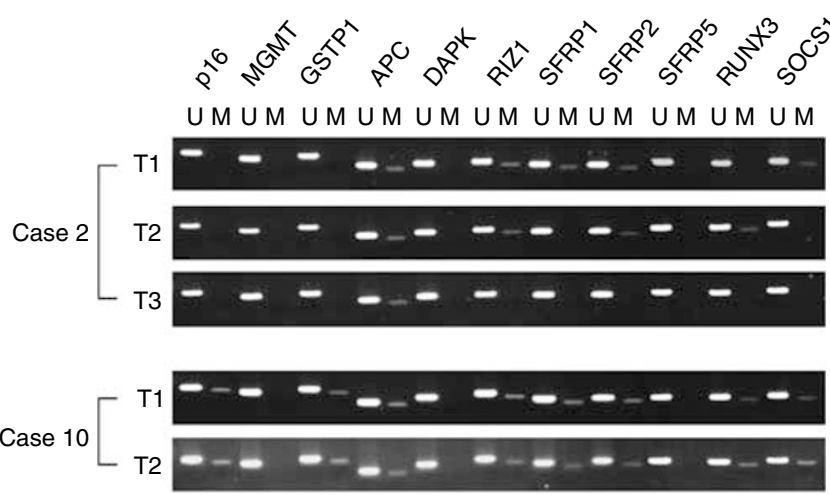

Figure I Representative cases of methylation status in multiple genes provided by methylation-specific PCR in tumour and corresponding normal tissue in patients with multicentric HCC. The different pattern of methylated genes in each tumour shows an independent occurrence in case 2 . When the aberrant methylation in the same genes was shown in both tumours in case 10, the judgement was metastases.

HCC or other types of cancer tissues by MSP. When an appropriate band was seen on a gel by loading the product of MSP, the methylation status was considered to be positive. The frequency of methylation in tumour tissue was as follows: $57.1 \%(24$ of 42$)$ in p16, $0 \%$ (0 of 42 ) in MGMT, 28.6\% (12 of 42) in GSTP1, 78.6\% (33 of 42 ) in APC, $2.4 \%$ ( 1 of 42 ) in DAPK, $45.2 \%$ (20 of 42 ) in RIZ1, $64.3 \%$ (27 of 42 ) in SFRP1, 59.5\% (25 of 42) in SFRP2, $28.6 \%$ (12 of 42 ) in SFRP5, 47.6\% (20 of 42) in RUNX3, and 54.8\% (23 of 42) in SOCS1. In noncancerous tissue, on the other hand, hypermethylation was found with the following frequency: $68.4 \%$ (13 of 19) in $A P C, 10.5 \%$ (2 of 19) in DAPK, 5.2\% (1 of 19) in RIZ1, 47.4\% (9 of $19)$ in SFRP $1,52.6 \%$ (10 of 19) in SFRP2, 10.5\% (2 of 19) in SFRP5, $10.5 \%$ (2 of 19) in RUNX3, and 2.5\% (1 of 19) in SOCS1. In addition, we checked the methylation status in 32 tumours with corresponding normal tissues from patients with single HCC. The methylated DNAs were detected with the following frequency: $65.6 \%$ ( 21 of 32 ) in p16, 3.1\% ( 1 of 32 ) in $M G M T, 31.3 \%$ ( 10 of 32 ) in GSTP1, $87.5 \%$ (28 of 32) in APC, $0 \%$ (0 of 32 ) in DAPK, $56.3 \%$ (18 of 32 ) in $R I Z 1,56.3 \%$ (18 of 32) in SFRP1, 53.1\% (17 of 32) in SFRP2, 28.1\% (9 of 32) in SFRP5, 46.9\% (15 of 32) in RUNX3, and $46.9 \%$ (15 of 32) in SOCS1. There were no significant statistical differences between cases of multiple HCC and single HCC. All cases examined in this study had methylation in at least one gene. The frequency of methylated cases in the studied genes is summarised in Table 2. The information on the patients and tumours is summarised in Table 3.

\section{Clonality by methylation or nonmethylation}

In all of the cases examined in this study, clonality was determined by the methylation status of $p 16, G S T P 1, A P C, R I Z 1, S F R P 1$, SFRP2, SFRP5, RUNX3, and SOCS1. MGMT and DAPK were not useful because of the low frequency of methylated cases. Basically, we judged that clonality had a different origin if the methylation status was different from the original tumour in at least one gene. In particular, if a second (or third) tumour had a loss of methylation in the same gene, it was considered an independent tumour. For example, in case 2, T2 had a loss of methylation in SOCS1 and SFRP1, and T3 had lost methylation additionally in RIZ1 and RUNX3 genes. It was therefore assumed that the tumours had a separate origin (Figure 1). Further, we supposed that a metastatic second (or third) tumour could have methylation in a gene even if the original tumour did not. For instance, the T2 tumour of case 17 was methylated in $p 16$ gene, although the first tumour did not have methylation in the gene. Clonality was determined by comparing the methylation status, with the result 


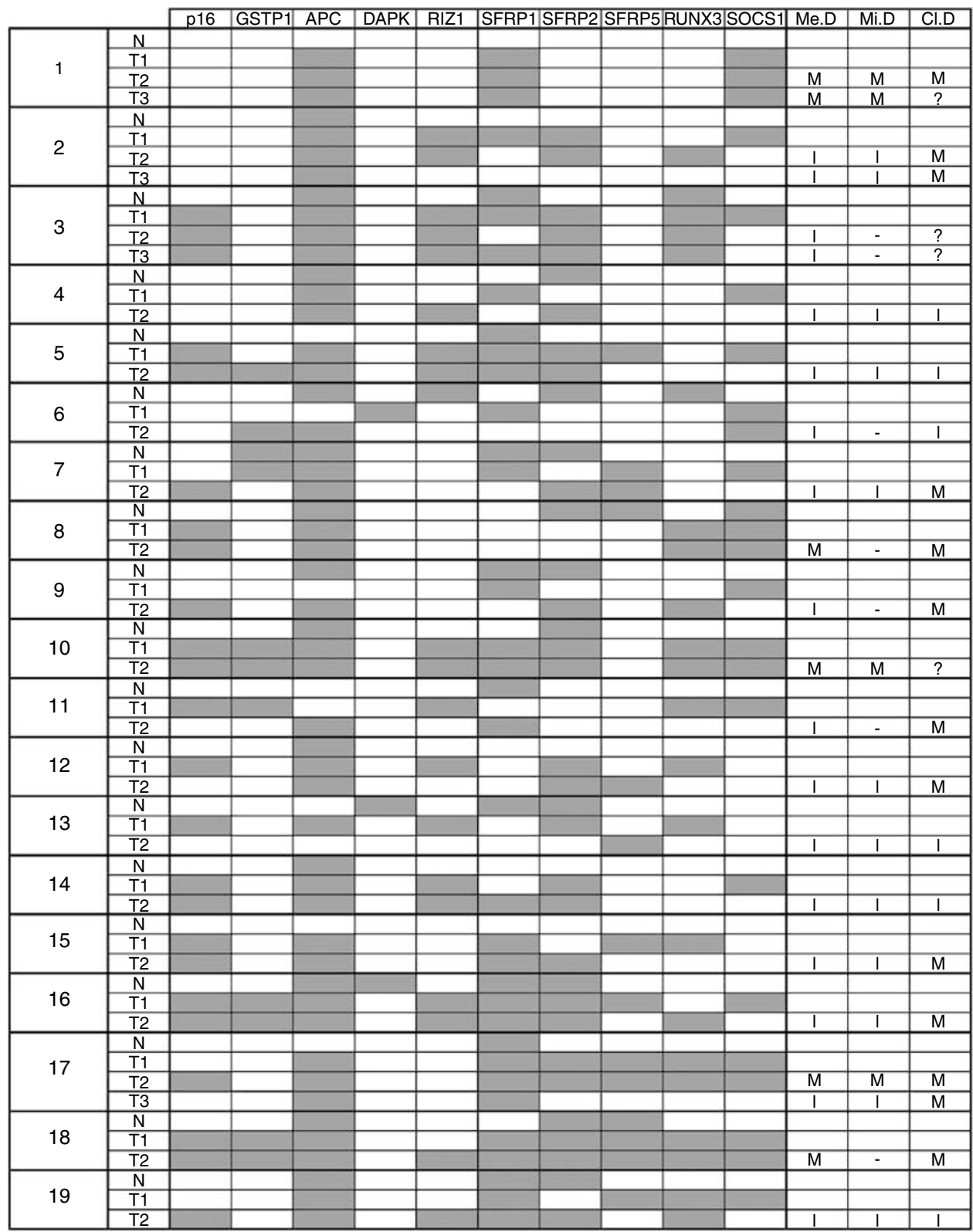

Figure 2 Summary of methylation of p I6, GSTPI, APC, DAPK, RIZI, SFRPI, SFRP2, SFRP5, RUNX3, and SOCS I in multiple HCC and corresponding normal tissues. Filled boxes indicate methylated loci. Open boxes indicate nonmethylated promoter loci. M, metastasis; I, independent lesion; ?, indeterminate. The largest tumour in the first operation was listed as the first primary lesion. Clonalities of mtDNA (Mi.D) were shown in a previous article (Nomoto et al, 2002). Clinical diagnosis (CI.D) was determined based on the Classification of Primary Liver Cancer in Japan. The results decided according to methylation status are shown in the column of Me.D. N, corresponding normal tissue; TI, original tumour; T2, second tumour; T3, third tumour.

being decided by the mutation in the mitochondrial genome. In cases where clonality could be determined by mitochondrial mutation, all of the results were consistent with the clonality decided by methylation status. In other cases, we could judge the clonalities in all tumours. Then, only 6 of $23(26.1 \%)$ tumours were determined to be metastases from the original tumour, although $68.4 \%$ (13 of 19 , excluding four undetermined cases) were supposed to be metastatic tumours from the clinical diagnoses. These results are summarised in Figure 2.

\section{DISCUSSION}

Hypermethylation of normally nonmethylated CpG islands in the promoter regions often occurs in important tumour suppressor genes such as VHL, hMLH1, and p16 (Herman et al, 1994, 1998; Merlo et al, 1995). In HCC tissues, frequent aberrant methylation in p16 gene was reported (Wong et al, 1999). Recently, loss of expression of other interesting genes, the detoxifying gene GSTP1 (Zhong et al, 2002) and $\mathrm{Rb}$ interact gene RIZ1 located within 1p36.13-p36.23, has been found in HCCs through promoter methylation ( $\mathrm{Du}$ et al, 2001). The DNA repair gene, $M G M T$, frequently inactivated in brain, colorectal, lung, and lymphomas (Esteller et al, 1999a), and the potential metastasis inhibitor DAPkinase gene altered in lymphomas, leukaemias, and lung cancer, were also reported with aberrant methylation (Katzenellenbogen et al, 1999; Esteller et al, 1999b). We reported frequent methylation in SOCS1 and another gene mapped at 1p36, RUNX3, in HCC tissues (Okochi et al, 2003; Mori et al, 2005). In addition, one of the major player genes involved in cancer development in the Wnt 
pathway, $A P C$, was also reported to show methylation-dependent silencing of expression (Esteller et al, 2000). Other Wnt signal genes in the SFRP family have been reported to have aberrant methylation in colon cancers (Suzuki et al, 2002). To our knowledge, ours is the first report regarding promoter hypermethylation in SFRP genes with HCC patients, and frequent methylation was confirmed in p16, GSTP1, RIZ1, SOCS1, and RUNX3. In addition, SFRP-1, -2 , and -5 genes were found frequently methylated in HCC tissue. In a DNA repair gene $M G M T$, no methylation was detected. We could detect very few instances of aberrant methylation in DAP-kinase because most of the tumours were independent lesions, not metastases. Interestingly, $A P C$ gene was commonly methylated in fully normal liver tissues $(88.2 \%, 15$ of 17$)$, and reduced methylation frequency was detected in cirrhotic liver and/or tissue in chronic hepatitis $(21.6 \%$, 11 of 51). After tumour development, the methylation status again became high $(82.4 \%, 61$ of 74$)$. This might be related to a potential for proliferation, and $A P C$ might have an important role in the regulation of regeneration. Loss of $A P C$ methylation in cirrhotic and inflammatory cases could possibly be due to infiltration of fibroblasts and/or inflammatory cells. In SFRP1 and SFRP2 genes, although very little aberrant methylation was shown in fully normal liver, frequent methylation was found in corresponding noncancerous tissues. Methylation in SFRP-1 and SFPR-2 genes might be related in premalignant situations or very early events in hepato-carcinogenesis.

Several studies are relevant regarding the clonality decision for multiple HCC. When judging by genetic mutations in p53 gene or mitochondrial genome (Oda et al, 1992; Nomoto et al, 2002), or by integrating the genomic pattern of hepatitis B virus (Yamamoto et al, 1999), the specificity of the decided clonalities was accurate. Considering sensitivity, the clonality decision was limited only to cases with mutations of the genes or tumours based on hepatitis B virus. We decided the clonality in all multicentric tumours using MSP in multiple tumour suppressor genes. It is worth mentioning that our method was successful in all cases, including cases 1 and 10 , which could not be determined clinically, in cases 12,16 , and 17 , where clinical diagnosis was clearly wrong (as confirmed by mitochondrial status), and even in cases 11 and 18, when mtDNA testing was noninformative. Regarding the sensitivity, this method is superior to both standard clinical acumen and all other molecular methods.

The specificity of our study is considered reliable because the results of the judgement were all consistent with the decisions that could be determined by mutations in the mitochondrial genome. Although the promoter hypermethylation event in tumour cells might be reversible, examining more than 10 genes improves the accuracy of the study.

Had we increased the number of tumour suppressor genes to be checked, which were frequently methylated in HCC tissue, it would have been more advantageous not only for determining clonality but also for assessing the malignant potential of the tumours. Most of the tumours are associated with a multistep process of development with changes in host gene expression (Feitelson et al, 2002). It could be very important to know the altered multiple pathways in a tumour for appropriate therapy in future.

Regarding the heterogeneity of HCC in a tumour, the mitochondrial mutation and the methylation status of 11 genes for DNAs obtained from five nonfatty parts of a tumour were checked, and the same mitochondrial mutation and similar methylation pattern were found in each DNA (data not shown). This might occur rarely in multiple genomic changes in a simple nodular HCC like the tumours examined in this study.

Surprisingly, most of the relapsed tumours diagnosed as metastases by clinical and pathological findings were determined to be independent lesions. These findings imply that any region of the liver where HCCs occurred has a potential for recurrence, because most of the HCCs are considered to grow on the basis of cirrhotic liver or chronic hepatitis. After further research on the liver stem cells and reducing the risks of operation, transplantation might take the place of resection in the future. Currently, we have to confirm the clonality of multiple HCCs for the future direction of therapy.

We have clearly shown that the methylation status of multiple tumour suppressor genes in multicentric HCC is useful as a clonal marker. By increasing the number of cases and frequently methylated genes related to tumour initiation and progression, the clonality would be shown more certainly. Furthermore, studies on checking methylation and searching mutations in multiple tumour suppressor genes should be expanded to screen normal tissue obtained by biopsy from patients with cirrhotic liver or chronic hepatitis to determine which gene(s) are most related to tumour initiation. This would be an opportunity to prevent the development of HCC. A greater understanding of the molecular pathogenesis of HCC may yield new markers for tumour staging, for assessment of the relative risk of tumour formation, and provide new opportunities for therapeutic intervention.

\section{REFERENCES}

Chen YJ, Yeh SH, Chen JT, Wu CC, Hsu MT, Tsai SF, Chen PJ, Lin CH (2000) Chromosomal changes and clonality relationship between primary and recurrent hepatocellular carcinoma. Gastroenterology 119: $431-440$

Du Y, Carling T, Fang W, Piao Z, Sheu JC, Huang S (2001) Hypermethylation in human cancers of the RIZ1 tumor suppressor gene, a member of a histone/protein methyltransferase superfamily. Cancer Res 61: 8094-8099

Esteller M, Hamilton SR, Burger PC, Baylin SB, Herman JG (1999a) Inactivation of the DNA repair gene O6-methylguanine-DNA methyltransferase by promoter hypermethylation is a common event in primary human neoplasia. Cancer Res 59: 793-797

Esteller M, Sanchez-Cespedes M, Rosell R, Sidransky D, Baylin SB, Herman JG (1999b) Detection of aberrant promoter hypermethylation of tumor suppressor genes in serum DNA from non-small cell lung cancer patients. Cancer Res 59: 67-70

Esteller M, Sparks A, Toyota M, Sanchez-Cespedes M, Capella G, Peinado MA, Gonzalez S, Tarafa G, Sidransky D, Meltzer SJ, Baylin SB, Herman JG (2000) Analysis of adenomatous polyposis coli promoter hypermethylation in human cancer. Cancer Res 60: 4366-4371

Feitelson MA, Sun B, Satiroglu Tufan NL, Liu J, Pan J, Lian Z (2002) Genetic mechanisms of hepatocarcinogenesis. Oncogene 21: 2593-2604

Goelz SE, Hamilton SR, Vogelstein B (1985) Purification of DNA from formaldehyde fixed and paraffin embedded human tissue. Biochem Biophys Res Commun 130: 118-126

Herman JG, Latif F, Weng Y, Lerman MI, Zbar B, Liu S, Samid D, Duan DS, Gnarra JR, Linehan WM, Baylin SB (1994) Silencing of the VHL tumorsuppressor gene by DNA methylation in renal carcinoma. Proc Natl Acad Sci USA 91: $9700-9704$

Herman JG, Umar A, Polyak K, Graff JR, Ahuja N, Issa JP, Markowitz S, Willson JK, Hamilton SR, Kinzler KW, Kane MF, Kolodner RD, Vogelstein B, Kunkel TA, Baylin SB (1998) Incidence and functional consequences of hMLH1 promoter hypermethylation in colorectal carcinoma. Proc Natl Acad Sci USA 95: 6870-6875

Katzenellenbogen RA, Baylin SB, Herman JG (1999) Hypermethylation of the DAP-kinase $\mathrm{CpG}$ island is a common alteration in B-cell malignancies. Blood 93: 4347-4353

Lee WH, Morton RA, Epstein JI, Brooks JD, Campbell PA, Bova GS, Hsieh WS, Isaacs WB, Nelson WG (1994) Cytidine methylation of regulatory sequences near the pi-class glutathione $S$-transferase gene accompanies human prostatic carcinogenesis. Proc Natl Acad Sci USA 91: 11733-11737

Merlo A, Herman JG, Mao L, Lee DJ, Gabrielson E, Burger PC, Baylin SB, Sidransky D (1995) $5^{\prime}$ CpG island methylation is associated with 
transcriptional silencing of the tumour suppressor p16/CDKN2/MTS1 in human cancers. Nat Med 1: 686-692

Mori T, Nomoto S, Koshikawa K, Fujii T, Sakai M, Nishikawa Y, Inoue S, Takeda S, Kaneko T, Nakao A (2005) Decreased expression and frequent allelic inactivation of the RUNX3 gene at $1 \mathrm{p} 36$ in human hepatocellular carcinoma. Liver Int 25: 380-388

Nomoto S, Yamashita K, Koshikawa K, Nakao A, Sidransky D (2002) Mitochondrial D-loop mutations as clonal markers in multicentric hepatocellular carcinoma and plasma. Clin Cancer Res 8: 481-487

Ochiai T, Urata Y, Yamano T, Yamagishi H, Ashihara T (2000) Clonal expansion in evolution of chronic hepatitis to hepatocellular carcinoma as seen at an X-chromosome locus. Hepatology 31: 615-621

Oda T, Tsuda H, Scarpa A, Sakamoto M, Hirohashi S (1992) Mutation pattern of the p53 gene as a diagnostic marker for multiple hepatocellular carcinoma. Cancer Res 52: 3674-3678

Okochi O, Hibi K, Sakai M, Inoue S, Takeda S, Kaneko T, Nakao A (2003) Methylation-mediated silencing of SOCS-1 gene in hepatocellular carcinoma derived from cirrhosis. Clin Cancer Res 9: 5295-5298
Suzuki H, Gabrielson E, Chen W, Anbazhagan R, van Engeland $M$, Weijenberg MP, Herman JG, Baylin SB (2002) A genomic screen for genes upregulated by demethylation and histone deacetylase inhibition in human colorectal cancer. Nat Genet 31: 141-149

Wong IH, Lo YM, Zhang J, Liew CT, Ng MH, Wong N, Lai PB, Lau WY, Hjelm NM, Johnson PJ (1999) Detection of aberrant p16 methylation in the plasma and serum of liver cancer patients. Cancer Res 59: 71-73

Yamamoto T, Kajino K, Kudo M, Sasaki Y, Arakawa Y, Hino O (1999) Determination of the clonal origin of multiple human hepatocellular carcinomas by cloning and polymerase chain reaction of the integrated hepatitis B virus DNA. Hepatology 29: $1446-1452$

Yoshikawa H, Matsubara K, Qian GS, Jackson P, Groopman JD, Manning JE, Harris CC, Herman JG (2001) SOCS-1, a negative regulator of the JAK/STAT pathway, is silenced by methylation in human hepatocellular carcinoma and shows growth-suppression activity. Nat Genet 28: 29-35

Zhong S, Tang MW, Yeo W, Liu C, Lo YM, Johnson PJ (2002) Silencing of GSTP1 gene by CpG Island DNA hypermethylation in HBV-associated hepatocellular carcinomas. Clin Cancer Res 8: 1087-1092 